\title{
Stativity and present tense epistemics *
}

\author{
Gillian Ramchand \\ University of Troms $\phi / C A S T L$
}

\begin{abstract}
Some modals are ambiguous between epistemic and circumstantial interpretations, but allow epistemic readings only when they combine with stative verb phrases. For other modals, the epistemic reading is not so constrained. I propose a theory of modal semantics that is sensitive to height of merge position and by extension the properties of the situational description that the modal combines with. To capture the pattern, modals are argued to have two important dimensions of meaning: (i) they will describe a topic situation asserted to be either an exhaustive or nonexhaustive choice over live situational alternatives; (ii) they will either anchor that topic situation indexically, or anaphorically. Modal meaning can then systematically interact with situational descriptions to build different interpretations while keeping the underlying semantics of the modal the same. Epistemic readings emerge when a modal attaches above the height at which temporal parameters of the situation are bound, circumstantials attach below the temporal specification. State-constrained epistemic modals are those that have indexical anchoring properties.
\end{abstract}

Keywords: modality, epistemics, statives, choice, alternatives, situations, indexicality

\section{Epistemic modality and the stativity puzzle}

There are a number of well known linguistic environments where English shows a strong state vs. event distinction, lumping together dynamic eventualities of different telicity specifications against states (see Bohnemeyer \& Swift 2004 for a classification of English in these terms, contrasting it with telicity sensitive languages). I briefly summarize some of these core well known facts here: (i) only states allow for a Universal reading of the perfect, where the eventuality is interpreted as continuing from a past time up to and possibly including the speech time (see Portner 2003); (ii) only states allow an ongoing at speech time interpretation for the present tense, while events require the progressive for the ongoing reading and get habitual readings in the present tense (Dowty 1979); (iii) in discourse sequencing, dynamic eventualities

* I would like to thank Hans Kamp, Yael Greenberg and Terje Lohndal for comments on earlier versions of this paper. I thank the reviewers and audience at SALT 24 for constructive feedback and discussion. There is not the space in this short article to do justice to all the ideas and implications worth pursuing that I have received from others. I leave such exploration to further work on this topic. 
Stativity and present tense epistemics

in English are non-overlapping (tending to advance the topic time), while states produce overlapping predications with the previously mentioned eventuality (see Kamp \& Rohrer 1983 for Romance). Thus, English shows robust language internal evidence for a split between stative and dynamic eventualities which affects their temporal interpretation in systematic ways. It is relevant to note that with respect to these tests, both progressives and perfects pattern as states in English (see also Hallman 2010), while passives pattern as dynamic events.

In this paper, I add the following novel empirical observation stated in (1) to this set of stativity sensitive phenomena in English:

Epistemic Stative-Sensitive (ESS) Modals:

ESS Modals are those that are technically ambiguous between an epistemic and circumstantial interpretation, but can only get that epistemic interpretation when combined with a stative prejacent.

An example of an ESS Modal, must, is shown in (2) below, where the epistemic reading only emerges with stative prejacents.

(2) a. Eeyore must be sad/in the field. (epistemic or obligational (future-oriented))

b. Eeyore must go to Christopher Robin's party. (only obligational)

An example of a non-ESS Modal, might, is shown in (3). Here, the epistemic reading is always available, regardless of the aktionsart of the prejacent.

a. Eeyore might be sad/in the field. (epistemic (present or future))

b. Eeyore might go to Christopher Robin's party. (epistemic (present))

Another way of putting the generalization is in terms of the orientation of the modal anchor, in the sense of Condoravdi (2002): in the case of ESS Modals, the possibility of an epistemic reading correlates with the present orientation of the modal anchor, while in the non-ESS Modal it does not.

If we combine modals with different varieties of prejacent (i.e. VPs of different types), we find that the possibility of an epistemic reading comes and goes predictably. If we consider the modal must below, we see that stative lexical verbs, statives formed with be and an AP or PP, progressives, perfects and habitual interpretations of dynamic verbs all allow epistemic interpretations side by side with the deontic must reading. Episodic readings of non-stative verbs (whether activities, accomplishments or achievements), and the eventive passive VP only give rise to a deontic reading under must. See the examples in (4).

a. John must like brussel sprouts very much!

STATIVE LEXICAL Readings: epistemic (present); deontic 
Ramchand

b. John must really hate getting up early!

StATIVE LEXICAL VERB Readings: epistemic (present); deontic

$\mathrm{BE}+\mathrm{PP} / \mathrm{AP}$

c. John must be in his office/tired. Readings: epistemic (present); deontic

d. John must be running the marathon (right now). Readings: epistemic (present/future); deontic

Progressive

e. John must have seen that movie already.

PERFECT Readings: epistemic (past); deontic

f. John must work hard for a living.

HABITUAL Readings: epistemic (present); deontic (future)

g. John must run to the store.

DYNAMIC ACTIVITY Readings: deontic (future)

$\mathrm{h}$. John must build a very big house.

DYNAMIC ACCOMPLISHMENT Readings: deontic (future)

i. John must win the race. DYNAMIC ACHIEVEMENT Readings: deontic (future)

j. John must be arrested/be chased by the police. Readings: deontic (future)

The reader can verify for him/herself that the negated English modal can't, which also allows both epistemic and circumstantial readings (this time the latter is a permission deontic or ability modal) shows the same split in the data: sentences corresponding to (4a)-(4f) are ambiguous between epistemic and circumstantial readings, while $(4 \mathrm{~g})-(4 \mathrm{j})$ allow only the circumstantial. ${ }^{1}$ Another modal which seems to pattern this way is the so-called future auxiliary will, for which we can also distinguish two distinct readings: one is the future reading, which I will assume with Copley 2002 is a circumstantial modal reading, and the other is an inferential reading, which is a form of epistemic modality. (Don't try calling John, he will be on the train now. (inferential) vs. John will be on the first train tomorrow (prediction)). The relevant observation is that here too, the inferential reading disappears with non-stative prejacents.

The epistemic readings are essentially readings that concern the speaker's knowledge state at the present moment, while the circumstantial modal readings quantify

1 It is a bizarre quirk of English can that the epistemic reading is not available in its positive polarity version. I have no explanation for this, but I note that like other negative polarity items the epistemic reading is also licensed with can used in a yes-no question. The reader can check that if the positive yes-no question versions of $(4 \mathrm{a})-(4 \mathrm{j})$ above are constructed, the same pattern of epistemic readings emerges. The fact that this pattern tracks the must pattern, following neatly the independent epistemic licensing quirk of can, shows that the epistemic reading itself is a conditioning factor. 
Stativity and present tense epistemics

over future oriented events. In the patterns we have seen above, the epistemic readings arise only from stative or derived stative predications, while the circumstantial readings are possible with both events and states.

On the other hand, the epistemic readings of other modals such as might, should and could do not seem to care about the stativity of the prejacent complement, as the following examples for might show, as in (5). Once again the reader is invited to verify that the corresponding pattern holds for should and could as well.

a. John might like brussel sprouts very much!

STATIVE LEXICAL Readings: epistemic (present/future)

b. John might really hate getting up early! Readings: epistemic (present/future)

c. John might be in his office/tired.

$\mathrm{BE}+\mathrm{PP} / \mathrm{AP}$ Readings: epistemic (present/future)

d. John might be running the marathon right now.

PRogressive Readings: epistemic (present/future)

e. John might have seen that movie already.

PERFECT Readings: epistemic (past)

f. John might work hard for a living.

HABITUAL Readings:epistemic (present/future)

g. John might run to the store.

DYNAMIC ACTIVITY Readings: epistemic (future)

h. John might build a very big house. Readings: epistemic (future)

i. John might win the race.

DYNAMIC ACHIEVEMENT Readings: epistemic (future)

j. John might be arrested/be chased by the police.

PASSIVE Readings: epistemic (future)

The generalization is as follows: modals such as should, could and might allow an epistemic reading even for dynamic verbs (non-ESS Modals), but modals like must, will or can only allow an epistemic reading for states (ESS modals). Thus the choice of modal base is influenced by the aspectual properties of the prejacent for ESS type modals only. For a modal like must in English, an epistemic modal base is only available if the prejacent is a state, while eventive prejacents give rise to a circumstantial modal base. This generalization requires interpreting the perfect tense in English as a kind of derived state, following Parsons (1990) and Kamp \& Reyle (1993), and indeed it patterns with states with respect to the diagnostics shown earlier. Past evaluation time of the prejacent event is only possible with perfects in 
English, but this is consistent with the intepretation of the epistemic quantification as over present knowledge states of the speaker (see Hacquard 2007), if the perfect denotes a derived resultant state with implications for the past instantiation of the event proper. Under this view, the progressive is also a derived state (as has been argued recently in Hallman 2010), as is the habitual.

The use of the term stative to pick out the critical natural class for must, is of course already an interpretation of the facts. For those who remain sceptical, I offer a purely morphosemantic alternative description of the generalization: for Type I modals like must, if the (possibly derived) verbal prejacent could possibly have occurred felicitously with the English simple present tense, then it can also get an epistemic reading with that modal. Here's the bottom line. Epistemic must, can't and will have the same distributional fingerprint as the simple present tense in English. Epistemic might, should and could do not.

Thus, the data pattern here presents us with a couple of analytical problems that we would like to solve. Firstly, we would like to have a constrained theory of modal compositional interpretation that combines with an analysis of stativity so as to derive the distribution of epistemic interpretations shown above. Secondly, we need an account of the role of the specific modal lexical contribution in delivering this result, given that not all modals are ESS Modals.

\section{Background on modal compositional interpretation}

Following the foundational work of Kratzer (1981) etc., modals in natural language have been claimed to be lexically distinguished with respect to a number of different dimensions: (i) quantificational force, i.e. universal vs. existential; (ii) constraints on the type of modal base they are compatible with; (iii) nature of the preferential ordering relations among members of the modal base. Hacquard 2006, and subsequent papers have already made an important and influential proposal extending the Kratzerian system to account for generalizations at the syntax-semantics interface. In particular, Hacquard is at pains to reconcile the elegance of the Kratzerian system where a single underspecified meaning can handle both epistemic and root interpretations, with the results of linguistic typology (cartography) which suggest the generalization that epistemic readings attach higher in the clause, outside tense, and root meanings attach inside tense. She proposes a system which ties particular types of interpretation to height in the structure. Her idea is to replace the base world from which the modal base is calculated with an event instead, and relate the semantic differences to differences in event anchoring, which is sensitive to the height of the modal in question. Specifically, she claims: (i) when the modal is speaker-oriented, it is keyed to the speech time and receives an epistemic interpretation; (ii) when the modal is attitude holder-oriented, it is keyed to the attitude time and receives an 
Stativity and present tense epistemics

epistemic interpretation: (iii) when the modal is subject-oriented, it is keyed to the time provided by tense and receives a root interpretation. Hacquard otherwise keeps intact the central structure of the Kratzerian solution: modals are functions from sets of possible worlds to sets of possible worlds; a restriction via contextually defined modal bases, ordering sources, existential vs. universal quantification. However, as it stands, the Hacquard account does not allow us either to understand the state sensitivity of the epistemic reading, or to distinguish between ESS and non-ESS modals in a principled way.

In other words, why does the epistemic reading go away in (6) but not in (7)?

a. John must be in his office.

b. John must go to the party.

(7) a. John might be in his office.

b. John might go to the party.

To capture the core intuition behind the generalization, I will explore a rather different model for modal interpretation that makes the modals themselves more like tense in a certain respect: both modals and tense predicates will be argued to combine with situational descriptions to create richer, modified situation descriptions. Secondly, I will shift some of the work done by the contextual component in classical theories into the compositional semantics directly. The interpretation of the modal will be directly sensitive to height via the properties of its complement (the constituent it combines with), as opposed to via the accessibility of different event binders for contextual variables, as in Hacquard's account. Perhaps the most radical part of the analysis will be the shift in semantic force of the modal itself that the compositional account necessitates. Specifically, I will argue that modals should be seen as operators over situational alternatives, involving the notion of CHOICE as a primitive notion, and relativized to a TOPIC for the choice. The contextual component will remain in the explication of the GROUNDS for the choice in question, which will be the placeholder for all the semantic work currently done by modal bases and ordering sources.

Essentially, in trying to solve the problem at the syntax-semantics interface, I am forced to rethink the balance between the relative contributions of structure vs. lexical presuppositional information and contextual information.

\section{Modals as choices over situational 'alternatives'}

The standard conception of tense and modality is that the former category is a relation between times/intervals (the topic time and the utterance time) and that the latter is a quantifier over possible worlds. 
a. $[[\text { must } \alpha]]^{w}=1$ iff $[[\alpha]]^{w^{\prime}}$ for all $\mathrm{w}^{\prime}$ that are accessible from $\mathrm{w}$.

b. $[[\text { past } \alpha]]^{t}=1$ iff $[[\alpha]]^{t^{\prime}}$ for some $\mathrm{t}^{\prime}$ that precedes $\mathrm{t}$.

Departing from the standard conception, I will follow Kratzer (2008) in claiming that propositions are not sets of possible worlds, but are rather characteristic functions (sets of) of situations. Situations are the key variable that all propositional operators modify equally.

Note that situations have time and location parameters and belong to particular possible worlds in this system. They are smaller and more specific than worlds, and have no transworld reality except via the 'counterpart' relation of Lewis (1986).

“... sentences are built from smaller constituents with propositional contents and that tenses, as well as temporal and locative adverbials, can be uniformly analysed as propositional operators successively imposing constraints on the situations that are being described. .... Tenses and temporal operators do no longer describe, refer to, or quantify over times. Situations have taken the place of times. The meaning assignments for past and present I gave earlier reflected this 'timeless' perspective on tenses." (Kratzer 2008: 47-48)

To give a concrete example, the reinterpreted tense predicates from Kratzer are given below.

a. [[ past ]] $]^{c}=\lambda \mathrm{p} \lambda \mathrm{s}\left[\mathrm{s} \approx \mathrm{s}_{\text {past }, c} \& \mathrm{p}(\mathrm{s})\right]$ where $\mathrm{s}_{\text {past }, c}$ is the unique situation s such that $\mathrm{s} \leq_{\text {in }} \mathrm{f}_{\text {Past }}\left(\mathrm{s}_{c}\right)$ and $\mathrm{s}$ is a topic situation at $\mathrm{s}_{c}$. Undefined if there is no such situation.

b. [[ present ] ] $]^{c}=\lambda \mathrm{p} \lambda \mathrm{s}\left[\mathrm{s} \approx \mathrm{s}_{\text {present }, c} \& \mathrm{p}(\mathrm{s})\right]$ where $\mathrm{s}_{\text {present }, c}$ is the unique situation s such that $\mathrm{s} \leq_{\text {in }} \mathrm{f}_{N o w}\left(\mathrm{~s}_{c}\right)$ and $\mathrm{s}$ is a topic situation at $\mathrm{s}_{c}$. Undefined if there is no such situation.

Similarly, we could also model modal operators as quantifying directly over situations instead of the possible world parameter directly. Kratzer argues that if modals truly quantified over the world variable alone it should be possible to find modal operators that quantified over the world variable of a world, time, location triple while keeping the place and/or time intact. She argues that no such modals exist, so the variables cannot be independent of each other, and shows how the modal interpretations can be rewritten in terms of situational variables. While I will not adopt the specific Kratzer style denotations for modals, the move to situations will be an important component in the analysis, because it allows temporal and modal operators to combine with entities of the same denotational sort without failure of compositionality, while still allowing differences between situational descriptions 


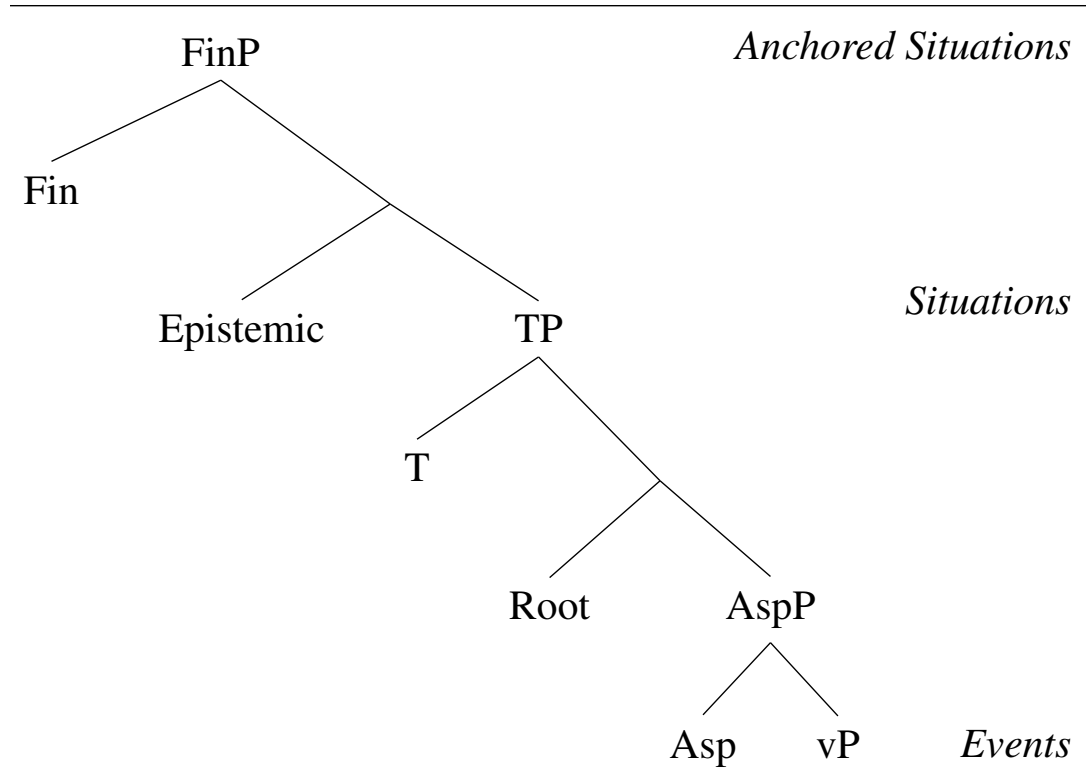

Figure 1 Mapping between syntactic height and semantic sort

that will feed different final interpretations. I will postpone the proposal for the actual modal denotations until the next section.

Given the typological linguistic generalizations linking phrase structural height to interpretation, we also need to establish how the semantics matches up to the syntax in a systematic way. Once complex sortal entities such as situations are granted in the semantic ontology, we can use entities of different sortal complexity to track the denotational properties of the functional sequence, under the assumption that the syntax builds descriptions of increasingly complex sortal units. The recent theory of Ramchand \& Svenonius (in press) proposes specifically that the lowest, first phase of the extended verbal projection builds event descriptions; the middle inflectional zone embodies a sortal shift to situational descriptions, and the highest $\mathrm{CP}$ zone denotes descriptions of situations that are anchored (by establishing some concrete relation to the Kaplanian context, or utterance situation). The functional sequence and its mapping to semantic sorts is shown in Fig. 1 below.

The notion of a topic situation being anchored to a context situation is a straightforward extension of neo-Reichenbachian theories of tense/aspect whereby a reference time or topic time (see Klein 1994 and Demirdache \& Uribe-Etxebarria 2008) is the intermediary between the utterance time and the event. 


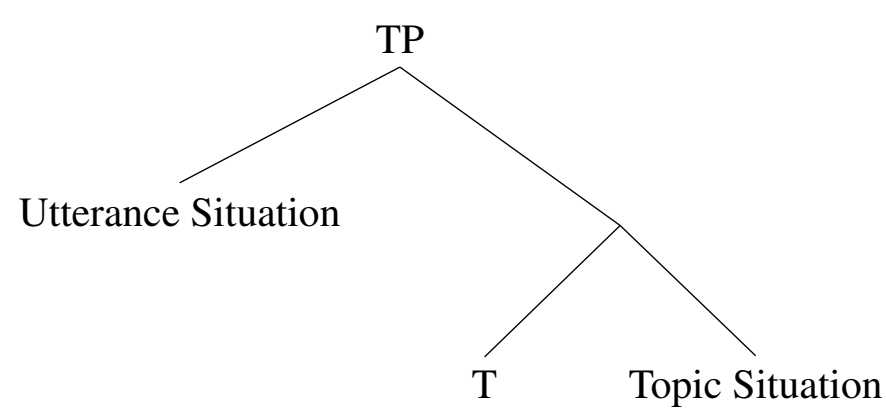

Figure 2 TP as the locus of generalized situational anchoring

Under this view, the $\mathrm{T}$ head combines with a situational description (the Topic situation) and establishes a relationship between it and the utterance situation (see Figure 2). I will call this anchoring, and assume that tense relationships are just one possible instantiation of the anchoring relation (see Ritter \& Wiltschko 2009).

In fact, the notion of utterance situation needs to be generalized to anchor situation to accommodate embedded attitudes and indirect discourse. I will assume that in general, an utterance has truth conditions only once it has been anchored, i.e. the situational description is embedded in the world via the utterance context $\mathrm{c}$. There are no propositions until we get to this point, only situational descriptions of more or less specificity. I will use the notion of support of a situational description $\mathrm{s}$ in a context $\mathrm{c}$ to correspond to propositional assertion in the classical sense.

$[[\mathrm{C}]]^{g, c}=\lambda \mathrm{P} \exists \mathrm{s}[\mathrm{P}(\mathrm{s}) \& \mathrm{c}$ supports $\mathrm{s}]$

which means that the context $\mathrm{c}$ is an information state that entails the truth of a situation $\mathrm{s}$ with the descriptive content $\mathrm{P}$.

In what follows, I will also use the * notation to indicate the parameters in the anchoring context $\mathrm{c}, \mathrm{t}^{*}=$ anchor time and $\mathrm{w}^{*}=$ anchor world. Under normal matrix conditions, this will simply be the utterance time, and the actual world respectively, but I assume that this can be relativized to deal with embedded attitudes and free indirect discourse.

\subsection{Live Alternatives}

Alternatives are needed in the explication of natural language in the domains of focus, calculation of implicatures and interrogative sentences (Rooth 1985, Rooth 1992, Hamblin 1973, Ramchand 1997), and possibly also for certain kinds of indefinites (Kratzer \& Shimoyama 2002). They have also been used recently to understand disjunction under modals, and in analyzing imperatives (Aloni 2007). Having said 
Stativity and present tense epistemics

that, the nature of the alternatives that I need for my CHOICE predicates will be somewhat different from the kinds of alternatives that have been explored in the literature so far. Specifically, these are not going to be propositional alternatives, but alternative situational descriptions.

As far as semantic compositionality is concerned, the modal combines directly with a constituent that denotes a situational description of some sort. Thus, under this architecture, the semantic value of the complement of the modal is just a situational description (let us call it $\mathrm{s} 1$ for convenience). The situation that the modal combines with has some properties and qualities specified, and others as yet undetermined. Suppose Live Alternative situations are constructed by filling in the different possible values for the parameters of the situation that are left unresolved up to that point, and which, for the speaker, are still technically 'live', or 'in play' (ALT(s1)). (This idea is similar to the Internal Alternatives of Greenberg 2013 in the sense that it is an internal contextual variable that is being filled in.) Suppose then that what the modal asserts is that the situational description constructed so far belongs to the set of Live Alternatives constructed in this way. The proposal here takes seriously the idea that modal assertions are made from a background of uncertainty, where there are a number of different potential ways the world could be, but the speaker is making a choice among them (possibly for a variety of different reasons and purposes).

[[ Modal ] $]^{g, c}=\lambda \mathrm{P} \lambda \mathrm{x} \exists \mathrm{s} 1[\mathrm{P}(\mathrm{s} 1) \& \mathrm{~s} 1$ is a CHOICE for $\mathrm{x}$ in $\mathrm{c}]$, where $\mathrm{s} 1 \in \mathrm{ALT}(\mathrm{s} 1)$ and Alternative Semantic Value (ALT(s1)) $=\{\mathrm{s}: \mathrm{s}$ is a live alternative for 1 , created by substituting different values for the free contextual parameters of the situational description of s. \}

Now at this point, it may be objected that the notion of 'live' alternative is simply a replacement for the notion of possible world which is not philosophically or ontologically any simpler than the traditional way of thinking about things. I agree. The problem is not with the notion of possibility (which is obscure but uncontrovertibly real for any natural language semantics), but with its scope and constrained relation to the syntax. Possible worlds simply get into the picture too late for the modal base to be systematically sensitive to syntactic height in a compositional way. Helping myself to situational descriptions allows a number of architectural changes that are crucial to the implementation at the syntax semantics interface-it allows the space of possibilities in terms of worlds and times to be confined within a situational description, and be sensitive to the ways in which that situational description has already been constructed. Secondly, it allows the notion of 'live' alternative to manipulate not just world parameters, but also temporal and polarity properties of the constructed situation. A full exposition of the power of CHOICE combined with Live Alternatives is beyond the scope of this short paper. I 
will confine myself to what is necessary to show how it solves the analytic problem described in the first section of this paper, and leave the further implications of the idea to future work.

Live Alternatives are those that are intuitively logically still in play at the time of utterance/anchor situation. I will assume that alternatives always include polar alternatives to the event predicate (see also Aloni 2007). With respect to the time parameter, past times are considered to be not in play any more - they are decided in the sense of Werner (2006) and only present and future time choices for the $t$ parameter are eligible. I will assume that temporal alternatives are calculated with respect to a time variable $t_{0}$, which is the one that will be anchored to tense. This is my way of implementing the future orientedness of Live Alternatives with respect to the time variable that is eventually modified by tense. It is essentially a stipulation about what it means to be a Live Alternative-something I take to be a primitive in this system. ${ }^{2}$ Similiarly, counterfactual worlds, worlds known to be counterfactual at the time of the anchor situation, cannot be part of the the alternative semantic value.

In epistemic contexts, the modal attaches after the time parameter has been set. This restricts the alternatives to a particular time. Live Alternatives are thus going to be things that are still in play at that time. This is just going to be the existence or non-existence of the event described in $\mathrm{P}$.

The topic of the CHOICE must be another argument of the CHOICE relation. Something can be a choice for $\mathrm{x}$ if it is part of the things $\mathrm{x}$ is able to do, is allowed to do, or is logically possible for $x$ to do. The important thing is that the choices are relativized to the involvement of $\mathrm{x}$. In circumstantial modals, this $\mathrm{x}$ argument is usually the highest or external argument of the event in the situational description, but it can also be other arguments or even filled in contextually. In epistemic modals, the $\mathrm{x}$ argument is the attitude holder, and the choices are inferential choices. As in theories such as Hacquard 2006, the filling of this argument position is constrained by syntactic height.

Finally, universal vs. existential force for the modals is transformed in this system, so that it looks quite different but basically has the same effect. The socalled universal modals have an exhaustive semantics for the CHOICE relation between the ordinary semantic value and the alternative semantic value (s1 is the only choice for $\mathrm{x}$ in $\mathrm{c}$ ). The so-called existential modals have a non-exhaustive semantics for the CHOICE relation between the ordinary semantic value and the alternative-semantic value ( $\mathrm{s} 1$ is one choice for $\mathrm{x}$ in $\mathrm{c}$ ).

2 In other implementations, such as Condoravdi 2002, the temporal futurity of the event time with respect to the perspective time is also simply stipulated for root modality. My own stipulation is a slight improvement in the sense that it derives in part from modal height, although the definition of what it means for something to be a live alternative is still axiomatic. 
Stativity and present tense epistemics

\section{Size matters}

\subsection{Circumstantial modality}

I illustrate first with the modal have-to on its deontic interpretation as shown in (12).

(12) Mary has to go to the party.

To get the circumstantial reading, the modal merges with AspP, which denotes a property of situations (which I am claiming have both temporal and world parameters) which is specified to embed the event e denoted by the vP. Even though situations have time and world variables, unlike events, these parameters are unbound at this stage.

Here's the denotation of have-to ${ }^{3}$.

$\left[[\text { have-to }]^{g, c}=\lambda \mathrm{P} \lambda \mathrm{x} \exists \mathrm{s} 1_{e 1, t 1, w 1}[\mathrm{P}(\mathrm{s} 1) \& \mathrm{~s} 1\right.$ is the only CHOICE for $\mathrm{x}$ in $\mathrm{c}]$, where $\mathrm{s} 1 \in \mathrm{ALT}(\mathrm{s} 1)$

and Alternative Semantic Value (ALT(s1) $)=\left\{\mathrm{s}: \mathrm{s}=\mathrm{s}_{e, t, w}\right.$, where alternative values of e are e 1 and not-e1, alternative values of $t$ are $t \geq t_{0}$, and w ranges over possible worlds.

(The variable $t_{0}$ is the one that will be later anchored by tense.)

Higher up the tree, the temporal parameter $\mathrm{t}_{0}$ will be bound by the assertion, and the modal will be relativized to the temporal anchoring of the matrix clause, as in Hacquard 2006.

a. Mary has to go to the party.

$\mathrm{t}_{0}=\mathrm{t}^{*}$, and the situational alternatives are in the future of the utterance time.

b. Mary had to go to the party.

$\mathrm{t}_{0} \leq \mathrm{t}^{*}$, i.e. a specific moment/interval in the past of $\mathrm{t}^{*}$, and the situational alternatives are in the future of that time.

3 I am assuming that the variable for the individual $x$, who is the topic for the choice situation, is going to be filled by an argument of the event predicate in the normal case, but also sometimes by a general topic situational variable in other cases. The examples below show that the choice of $\mathrm{x}$ is not fully determined by the syntax.

(i) Mary has to go to the party.

(ii) Mary has to be in bed by 11 at the latest! (to the babysitter)

(iii) There has to be silence in the house when I am thinking!

A discussion of this aspect of the modal semantics is beyond the scope of this paper. 
There is obvious room in these definitions for different presupposed information or pragmatic contextual information about GROUNDS for why the topic for the choice situation has the choice he/she/it does. This framework is not intended to replace the contextual input to modal semantics. The contextuality of modal bases etc., has been relegated to the filling in of the notion GROUNDS for a choice, and can be made explicit by use of adverbials or retrieved from the context.

(15) Grounds for CHOICE coming from discourse context:

A: Oh no, I have a meeting at 9 a.m. tomorrow morning!

B. Then, you will have to get up before 8 for once.

Grounds for CHOICE coming from adverbial modification:

a. If you want to make that meeting, you will have to get up before 8 .

b. Because of the 9 a.m. meeting, she had to get up before 8 for once.

c. In view of my schedule tomorrow, I will have to get up before 8 for once.

The point here is not to deny the work done by contextual factors, but to change the architecture so that we get the kind of mapping between the syntax and semantics that will allow us to integrate modality more naturally with temporal interpretation. I do not see that the questions raised in this framework are any more difficult or different from the equivalent issues in more standard treatments.

\subsection{Epistemic modality}

Things are different when we consider what happens when we place the modal higher up in the clausal structure. If we base generate have-to higher than $\mathrm{T}$, we get the meaning shown in (17).

$[[\text { have-to }]]^{g, c}=\lambda \mathrm{P} \lambda \mathrm{x} \exists \mathrm{s} 1_{e 1, t 1, w 1}[\mathrm{P}(\mathrm{s} 1) \& \mathrm{~s} 1$ is the only CHOICE for $\mathrm{x}$ in $\mathrm{c}]$, where $\mathrm{s} 1 \in \mathrm{ALT}(\mathrm{s} 1)$

and Alternative Semantic Value Alt(s1) $=\left\{\mathrm{s}: \mathrm{s}=\mathrm{s}_{e, t 1, w 1}\right.$, where alternative values of e are e 1 and not-e1.\}

Here the assumption is that the modal combines with the situational description after the time and world parameters have been specified (as t1 and w1 respectively in the above formula). Thus, the alternatives involve only the polarity of the event. The speaker is asserting that the current context $\mathrm{c}$, supports only the positive polarity version of the situational description. Because they are making the claim both that the context supports ALT-s1 as live alternatives in principle, while simultaneously saying that only s1 is supportable, this makes the assertion of must modality both more explicit about actual choosing than an ordinary utterance of s1, and more indirect in asserting the truth of the prejacent (see von Fintel \& Gillies 2010). 
Stativity and present tense epistemics

\section{Modals and anchoring}

I have proposed a semantics that makes the epistemic vs. circumstantial readings of modals and their temporal properties follow from the height of attachment and the semantics of choice over live situational alternatives. Now it remains to account for the differences between must and might when it comes to the distribution of their epistemic readings. The difference here comes from anchoring properties of the modals in question.

Modals in English all behave distributionally as if they end up high in the clause: they invert in questions, they precede negation and do not require $d o$-support, and they are unique in the clause. I take these facts at face value and assume that, wherever the modal is actually base generated, it actually always ends up in the equivalent of Infl. What we assume from tense is that it is the job of this head to establish a relationship between the topic situation $\mathrm{s}_{t o p}$ and the situational anchor of the clause $\mathrm{s}^{*}$. The natural assumption then is that modals also must be endowed with information that establishes such a relationship. I assume moreover that this anchoring property of Infl, suitably generalized, is a universal property of natural language sentences, plausibly driven by constraints at the interpretational interface (Ritter \& Wiltschko 2009)

Generalized Anchoring (Informal):

I will assume that the topic situation must be anchored in some way to the utterance/anchor situation to make a well-formed utterance. A well formed utterance therefore always takes the logical form: c supports $\mathrm{s}$.

The idea here is that modals like must share a property with the present tense in being indexically bound to the utterance time. The anchoring difference between modals such as must and might is between INDEXICAL and ANAPHORIC, as defined in (19). ${ }^{4}$

(19) INDEX: $s=s^{*}$. The situational variable is identified directly with the deictic anchor, the utterance situation.

ANAPHORIC: s must have its reference resolved anaphorically, either by binding from something in the linguistic context, or to some purely discourse contextual topic situation.

4 The idea that modals in some sense do the same job as tense has echoes in the proposal found in Iatridou 2000 (see also Isard 1974) that past tense morphology is not a primitive tense category, but is one of the manifestations of the more general semantic category (REMOTE, in their terms). According to Iatridou (2000), the remote relation can relate worlds as well as times, accounting for some cases of past morphology on modals. Apart from the use of situations as variables, my proposal is different from Iatridou's in that I take INDEXICAL vs. ANAPHORIC to be the primary relational distinction, not IDENTITY vs. REMOTE. 
Note that anaphoric reference in this sense covers many different modes of reference resolution (being essentially negative); it is intended to mirror the cut in the pronoun system between indexical forms like I/you on the one hand, and non-indexical ones like he/she/it on the other, regardless of the means of reference assignment of the latter. It is well known that this is the cut that is almost universally instantiated crosslinguistically within pronoun systems.

Thus, in addition to its semantics of CHOICE constrained by alternatives, must also possesses information that anchors the situational description to the utterance situation by asserting an identity between the time and world variables of that situation with the utterance contextual ones, much like the English present tense (see 20).

$\left[[\text { must }]^{g, c}=\lambda \mathrm{x} \lambda \mathrm{P} \exists \mathrm{s} 1_{e 1, t^{*}, w^{*}}[\mathrm{P}(\mathrm{s} 1) \& \mathrm{~s} 1\right.$ is the only CHOICE for $\mathrm{x}$ in $\mathrm{c}]$, where $\mathrm{s} 1 \in \mathrm{ALT}(\mathrm{s} 1)$

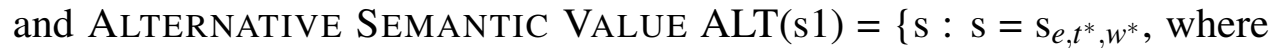
alternative values of e are e1 and not-e1.\}

On the other hand, might is not indexical in this sense, but anaphoric, and the temporal and world variables may be anaphorically resolved to a salient discourse interval, or identified with some linguistically present time via binding.

$[[\text { might }]]^{g, c}=\lambda \times \lambda \mathrm{P} \exists \mathrm{s} 1_{e 1, t 1, w 1}[\mathrm{P}(\mathrm{s} 1) \& \mathrm{~s} 1$ is one CHOICE for $\mathrm{x}$ in $\mathrm{c}]$, where $\mathrm{s} 1 \in \operatorname{ALT}(\mathrm{s} 1)$

and Alternative Semantic Value ALT(s1) $=\left\{\mathrm{s}: \mathrm{s}=\mathrm{s}_{e, t 1, w 1}\right.$, where alternative values of e are e1 and not-e1.\}

Thus, for might, even though it is epistemic in the sense of being about polarity alternatives alone, it is not confined to alternatives at the utterance time or world, since the situational parameters can be chosen pragmatically to be identical to some discourse salient at-issue time or world.

We can now answer the question of why the epistemic version of must is confined to stative complements. Notice that the denotation built up above includes the denotation for present tense (by assumption, the very same present tense found in simple clauses in English). However, we know that the English present tense is special in requiring a stative complement. In some sense it does not matter how we implement the semantic reason for this, as long as the reason is based directly on the denotation that the present tense and the epistemic reading given above have in common. However, I will assume a concrete explanation for this fact, directly building on Taylor (1977)'s original intuition:

(22) Events vs. States (inspired by Taylor 1977): (i) If $\alpha$ is a stative predicate, then $\alpha(\mathrm{x})$ is true at an interval I just in case $\alpha(\mathrm{x})$ is true at all moments within 
Stativity and present tense epistemics

I; (ii) If $\alpha$ is an eventive predicate, then $\alpha(\mathrm{x})$ is only true at an interval larger than a moment.

We now simply assume that this applies to the temporal parameter of situations in our sense: situations that have a point in time as their temporal parameter, can only embed states.

\section{Extensions}

The observant reader will have noticed that the non-ESS modals are the ones which host moribund tense morphology, and the ESS Modals by and large do not. One of the upshots of this paper has been to notice that the morphological facts of English modals, far from being historical detritus, actually do correspond to a systematic difference in the way in which the modal is integrated into the compositional semantics with respect to situational anchoring.

On the other hand, the negative specification of the anaphoric modals (the ones with moribund past tense morphology) is actually a very weak specification. All it does is refuse to identify the situational variable indexically, leaving it free to be resolved contextually. This is the reason why we cannot simply get away with specifying these modals as carrying a REMOTE feature with respect to the world variable, as in the system of Iatridou (2000). The problem is that empirically, there does not seem to be any problem with contextual binding of the outermost situational variable to a world time pair that overlaps with the present utterance time or is immediately subsequent to it, as in (23) below.

(23) John might/could be in his office now.

On the other hand, the idea that the situation variables must be resolved anaphorically when might/could is used, allows the resolution to target a situation that temporally overlaps with the utterance situation as a matter of contingent fact. Again, while this seems to be a very weak meaning for a modal, empirically might and could do indeed have this range of meanings, and pinning down the temporal anchoring more than this gives the wrong results.

However, there are other contexts where the anaphoric anchoring properties of might-like modals have an effect. Consider the following data. In the sentences in (24), the perspectival anchor for the modal interpretation is shifted to be identical with the event expressed in the matrix.

(24) a. John said that Mary could borrow his horse.

b. John said that Mary might borrow his horse.

c. John said that Mary should borrow his horse. 
d. John said that Mary would borrow his horse.

Crucially here, we can get an interpretation where the modal calculation is based on alternatives that fan out from the time of John's saying. In particular, these sentences are true if Mary indeed borrowed John's horse and has already returned it at the actual time of the speaker's utterance. Compare this with the corresponding sentences that embed indexical modals, as seen in (25).
a. John said that Mary can borrow his horse.
b. John said that Mary may borrow his horse.
c. John said that Mary must borrow his horse.
d. John said that Mary will borrow his horse.

To my ear, the versions with indexical modals are good only under a kind of double access reading - the borrowing of the horse event is in the future both of the saying event and the speech time. This follows under my proposal because, for non-ESS modals the temporal parameters of the choice situation can be dependent on the main clause parameters, and anaphorically bound. For ESS modals, the temporal parameters of the choice situation must be identified with the clausal anchoring parameters.

The second phenomenon where the difference between indexicality and discourse or anaphoric binding can show up is in the expression of counterfactuality. There is a class of modal sentences in English which show an interesting ambiguity that has been the topic of some recent work in the literature (Condoravdi 2002, Stowell 2004, Demirdache \& Uribe-Etxebarria 2008). The phenomenon concerns the readings that arise when a modal embeds a perfect auxiliary. Consider the sentence in (26), which is claimed to have at least two, and possibly three different readings.

(26) John could have won the race.

a. ... let's go and find out. (Epistemic reading)

b. ... but he didn't in the end. (Counterfactual reading)

c. ... (still) at that point. (Backshifted or metaphysical reading)

Accounts in Condoravdi 2002, Stowell 2004, Demirdache \& Uribe-Etxebarria 2008 all analyse the counterfactual reading as involving a scope reversal between PAST and modal (either in the syntax or the semantics).

But reversals overgenerate, empirically. The heart of the problem is that not all modals actually show the ambiguity; specifically, there are modals that allow only the epistemic reading and not the backshifted one, as in (27).

(27) a. John must have won the race.

Epistemic only 
Stativity and present tense epistemics

b. John will have won the race.

Epistemic only

c. Can John have won the race?

Epistemic only

a. John could have won the race. Counterfactual/backshifting possible

b. John might have won the race. Counterfactual/backshifting possible

c. John should have won the race. Counterfactual/backshifting possible

The epistemic uncertainty reading is straightforwardly predicted under the present account by allowing the perfect tense to denote a resultant state, and anchoring the epistemic alternatives to the utterance context. But how do the other two readings emerge and why are readings (25b) and (25c) only possible with the anaphoric modals in my terms? Once again the pattern is explicable under the view that for non-ESS modals, the temporal parameters of the chosen situation can be a counterfactual world (counterfactual reading), or past time (back shifted reading). For ESS modals, the temporal parameters of the chosen situation must be identified with the speech time. In the above cases the prejacent is a perfect auxiliary phrase, which, as we saw above, patterns with statives in describing a resultant stative situation with entailments about past time events.

\section{Conclusion}

To summarize, our puzzle concerning the syntax-semantics interface has caused us to shift and repackage traditional modal semantics into a new form. Modals have been argued to have two important dimensions of meaning: (i) they describe a topic situation asserted to be either an exhaustive or non-exhaustive choice over live situational alternatives; (ii) they either anchor that topic situation indexically, or anaphorically. This allows modal meaning to systematically interact with situational descriptions to build different interpretations while keeping the underlying semantics of the modal the same. Epistemic readings emerge when a modal attaches above the height at which temporal parameters of the situation are bound, circumstantials attach below the temporal specification. State-constrained epistemic modals are those that have indexical anchoring properties. The radical shift in the semantics of modals is not justified by any claimed superiority in accounting for truth conditions, but in providing a superior account of generalizations at the syntax-semantics interface.

\section{References}

Aloni, Maria. 2007. Free choice, modals, and imperatives. Natural Language Semantics 15. 65-94. 
Bohnemeyer, Juergen \& Mary Swift. 2004. Event realization and aspectual interpretation. Linguistics and Philosophy 27(3). 263-296.

Condoravdi, Cleo. 2002. Temporal interpretation of modals. modals for the present and for the past. In Stefan Kaufmann David Beaver, Luis Casillas \& Billy Clark (eds.), The Construction of Meaning, 59-87. Stanford, CA: CSLI Publications.

Copley, Bridget. 2002. The Semantics of the Future: Massachusetts Institute of Technology dissertation.

Demirdache, Hamida \& Myriam Uribe-Etxebarria. 2008. Scope and anaphora with time arguments: The case of 'perfect modals'. Lingua 118(11). 1790-1815.

Dowty, David R. 1979. Word Meaning and Montague Grammar: The Semantics of Verbs and Times in Generative Semantics and in Montague's PTQ. Dordrecht: Reidel.

von Fintel, Kai \& Anthony S. Gillies. 2010. Must...stay...strong! Natural Language Semantics 18(4). 351-383.

Greenberg, Yael. 2013. External and internal alternative-sensitive operators. Ms., Bar Ilan University.

Hacquard, Valentine. 2006. Aspects of Modality. Cambridge, MA: Massachusetts Institute of Technology dissertation.

Hacquard, Valentine. 2007. Speaker-oriented vs. subject-oriented modals: A split in implicative behaviour. Sinn und Bedeutung 11. 305-319.

Hallman, Peter. 2010. Instants and intervals in the event/state distinction. Ms., UCLA.

Hamblin, C. L. 1973. Questions in Montague English. Foundations of Language 10. 41-53.

Iatridou, Sabine. 2000. The grammatical ingredients of counterfactuality. Linguistic Inquiry 31(2). 231-2.

Isard, Steven. 1974. What would you have done if... Theoretical Linguistics 1. 233-255.

Kamp, Hans \& Uwe Reyle. 1993. From Discourse to Logic. Dordrecht: D. Reidel.

Kamp, Hans \& Christian Rohrer. 1983. Temporal reference in French. Ms. University of Stuttgart.

Klein, Wolfgang. 1994. Time in Language. London and New York: Routledge.

Kratzer, Angelika. 1981. The notional category of modality. In Hans-Jürgen Eikmeyer \& Hans Reiser (eds.), Words, Worlds and Contexts, 38-74. Berlin/New York: de Gruyter.

Kratzer, Angelika. 2008. Modals and conditionals again (chapter 2). Online version on website, University of Massachusetts, Amherst.

Kratzer, Angelika \& Junko Shimoyama. 2002. Indeterminate pronouns: The view from Japanese. 3rd Tokyo Conference on Psycholinguistics 1-25.

Lewis, David K. 1986. On the plurality of worlds. Oxford: Blackwell. 
Stativity and present tense epistemics

Parsons, Terence. 1990. Events in the Semantics of English: A Study in Subatomic Semantics. Cambridge, Ma.: MIT Press.

Portner, Paul. 2003. The temporal semantics and modal pragmatics of the perfect. Linguistics and Philosophy 26. 459-510.

Ramchand, Gillian. 1997. Questions, polarity and alternative semantics. North Eastern Linguistics Society (NELS) 27. 383-396.

Ramchand, Gillian \& Peter Svenonius. in press. Deriving the functional hierarchy. In press, Language Sciences, http://dx.doi.org/10.1016/j.langsci.2014.06.013.

Ritter, Elizabeth \& Martina Wiltschko. 2009. Varieties of infl: Tense, location and person. In Jeroen Craenenbroeck Hans Broekhuis \& Henk van Riemsdijk (eds.), Alternatives to Cartography, 153-202. Mouton de Gruyter.

Rooth, Mats. 1985. Association with focus: University of Massachusetts at Amherst dissertation.

Rooth, Mats. 1992. A theory of focus interpretation. Natural Language Semantics 1(1). 75-116.

Stowell, Tim. 2004. Tense and modals. In Jacqueline Guéron \& Jacqueline Lecarme (eds.), The Syntax of Tense and Aspect, 621-636. Cambridge, MA: MIT Press.

Taylor, Barry. 1977. Tense and continuity. Linguistics and Philosophy 1.2. 199-220. Werner, Tom. 2006. Future and nonfuture modal sentences. Natural Language Semantics 14(3). 235-255.

Gillian Ramchand

Linguistics Institute, Faculty for Humaniora, Social Sciences and

Education

University of Troms $\varnothing$

N-9037, Norway

gillian.ramchand@uit.no 